\title{
Test-Retest Reliability of Electroglottography Measurement
}

\author{
(1) Mehmet Emrah Cangi, (1) Göksu Yılmaz \\ Üsküdar University Faculty of Health Sciences, Department of Speech and Language Therapy, İstanbul, Turkey
}

Cite this article as: Cangi ME, Yılmaz G. Test-Retest Reliability of Electroglottography Measurement. J Acad Res Med 2021;11(2):126-36

\begin{abstract}
Objective: Electroglottography (EGG) is an instrumental measurement technique that provides a relative measure of the contact area between vocal folds. It is important to examine whether this measurement provides reliable data in Turkish. The aim of this study is to determine the level of reliability of EGG measurements made at different times related to some sustained vowel vocalizations.

Methods: Seventy participants, 35 women and 35 men, aged between $18-25$ and who have healthy voice, participated in the study. The Kay-PENTAX Electroglottograph model 6130 was used to study participants' production of /i/, /u/, / / / and / / / vowels. Data were collected from participants at four different time points: (1M) first week in the morning, (1E) first week in the evening, (2M) second week in the morning, and (2E) second week in the evening. The data obtained from all these measurements were matched in terms of time points; $1 \mathrm{M}-1 \mathrm{E}, 2 \mathrm{M}-2 \mathrm{E}, 1 \mathrm{M}-2 \mathrm{E}$ and $1 \mathrm{E}-2 \mathrm{E}$. The consistency between measurements of these time points was studied by the inter-class correlation coefficient (ICC), a two-way mixed model. The gender differences of the parameters were analyzed with independent samples t-test.

Results: According to repeated test results of all parameters obtained for the / $\varepsilon /$ vowel for both sexes and the /i/ vowel for men only, ICC values were statistically significant at levels ranging from moderate to excellent. In addition, when closed and open phase data were examined, values of all vowels did not differ according to gender during phonations. The frequency periodicity parameter of $/ \Lambda /, / \varepsilon /$ and $/ \mathrm{i} /$ vowels differs statistically significant in this respect. When the averages were examined, it was found that the measurements of women were higher than those of men in all parameters where significant differences were found.
\end{abstract}

Conclusion: As a result of repeated measurements with EGG, regardless of the recording time, measurements of the / $/ \varepsilon /$ vowel showed more reliable results compared to other vowels.

Keywords: Test-retest reliability, electroglottography, voice evaluation

\section{INTRODUCTION}

Voice disorders can be evaluated in many ways, including acoustic and glottographic techniques. In this context, electroglottography (EGG) method, which is a non-invasive and direct evaluation battery of the glottal cycle, is often used. EGG is based on the electrical conductivity of the vocal fold and surrounding tissues as a measurement principle. Measurements are performed through two electrodes placed on the surface of the laryngeal region. During the measurement, the person is asked to make a phonation, and a very low-amp current is passed through the electrodes by the device. As a result, a certain number of current passes through the folds that open and close during phonation. The value of this current measured by the electrodes, on the other hand, shows differentiation due to impedance, which is constantly variable depending on vocal fold movements. The electroglottographic wave form (Lx) obtained at the end of the measurement is an impedance change wave that reflects the movement of the vocal folds $(1,2)$.

ORCID IDs of the authors: M.E.C. 0000-0001-8149-3254; G.Y. 0000-0001-6123-8395.

Sorumlu Yazar/Corresponding Author: Mehmet Emrah Cangi, E-mail: mehmetemrah.cangi@uskudar.edu.tr

Presented in: It was presented as an oral presentation at the Voice-Istanbul Congress held at Medipol University in Istanbul on September 19-22, 2019.
Geliş Tarihi/Received Date: 23.10.2020 Kabul Tarihi/Accepted Date: 02.03 .2021

CC Copyright 2021 by University of Health Sciences Turkey, Gaziosmanpaşa Training and Research Hospital. Available on-line at www.jarem.org 
In voice evaluations, continuous vowel phonation is often used. Because during vowel phonation, many mixing factors such as accent, intonation, dialect are excluded, and these measurements are mostly performed with continuous vowel phonations, which are phonetically defined by $/ \mathrm{a} /, \mathrm{l} / \mathrm{/}$, and / $u /$ representations (3). In this context, it was defined by the International Phonetic Alphabet and the productions of all vowels available in terms of phonetics are classified in terms of tongue, lip and jaw movements. The production of different vowels, on the other hand, is due to these differences, which occur according to the place of articulation. Sustained vowel phonations, mostly used for voice evaluation, can alter laryngeal position and vocal tract acoustics due to differences occurring relative to the place of articulation $(3,4)$. In this case, acoustic and/or electroglottographic evaluation parameters can affect the evaluation and therapy process of voice disorders, resulting in different values in different vowel phonations.

Different hypotheses have been proposed to explain the effect of different vowels, often used in voice evaluation procedures, on acoustic perturbation and fundamental frequency values. According to the acoustic coupling (source-filter) hypothesis, perturbation parameters should not be affected by the filter change that occurs during the articulation of different vowels because the source retains its existence without any structural change $(5,6)$. The physical connection hypothesis, on the other hand, is studied in three separate subheadings: tongue pull, tongue compression, and horizontal-vertical pull. The hypothesis holds that there is a physiological-anatomical relationship between the vocal tract and the larynx, which changes acoustically during vowel phonations that differ according to their place of articulation. Research conducted in this context has shown that differences in tongue position or hyoid-larynx complex are related to basic frequency and perturbation parameters $(7,8)$. In short, the configuration of the vocal path filter during different vowel phonation varies based on the differentiation of their placement relative to each other, and it has been determined that these differences in the vocal path affect the acoustic perturbation parameters of the voice analyzed $(7,9)$.

In clinical use, if observed changes in electroglottographic parameters (effectiveness of therapy, degree of pathology progression, etc.) are to be used as an objective predictor of voice quality, knowing under what conditions the reliability between measurements is most optimal within the framework of variations created in terms of time and vowel type of people with normal voice will provide a great advantage for clinical use. In this context, there are a number of studies in the literature examining the reliability levels of aerodynamic and/or electroglottographic parameters of repeated measurements (10-16).

The aim of the current research is to determine the degree of reliability of EGG values obtained from different vowel phonations and measurements made at different times in terms of parameters determined as a result of repeated tests and to compare the obtained parameters in terms of gender.

\section{METHODS}

\section{Participants}

The study included 70 participants, 35 women and 35 men, between the ages of 18 and 25. Due to the fact that the participant population is university-level students, the age range of participants is 18 to 25 years. The power analysis was calculated using version G-Power 3.1 based on the gender variable. It was found appropriate to include at least 58 participants, including at least 29 in each group, in the power analysis performed by Awan et al. (14) considering the effect size in the analysis in which the differentiation of mean F0 according to gender was examined, with a power of $95 \%$ in the $95 \%$ confidence interval. In the study, 70 participants were reached and the required sample size was provided. For the purposes of the study, some participant exclusion criteria were determined. Individuals with any structural abnormalities in the head and neck region or a history of surgery, chronic larynx disease, taking a drug that requires constant use, smoking, long-term voice disorders, and hearing disorders were not included in the study. In addition, individuals with lower or upper respiratory infections, seasonal allergies, or complaints about their voice during the measurement were not included in the study. Professional voice users and individuals who had previously received singing or voice therapy were also not included in the study. For female participants, the criteria for not being in the menstrual cycle was determined during the measurement.

It is based on the statements and anamnesis of the participants in the exclusion criteria in which they have a normal voice, but on the perceptual assessment of the researcher conducting the recording process. Accordingly, the authors conducted preliminary evaluations of the participants and participants who met the criteria for the frequency periodicity value for EGG measurement to be less than 20 were included in the study.

This study is planned in accordance with the International Declaration of Helsinki. A written consent form was obtained from all of the individuals who agreed to participate in the study, and the participants were informed about the content of the study. For the study, Ethics Committee approval was obtained from Üsküdar University Non-interventional Research Evaluation Board (decision no: 61351342-/2019-216, date: 25.04.2019).

\section{Recording Procedures}

First, the purpose of the study was explained to the participants and written consent was obtained from them. Then, sociodemographic information was taken with the personal information form and information about the participant criteria was provided. In the directive presented to the participants, they were asked to specifically avoid behaviors that may negatively affect vocal hygiene at least 24 hours before each measurement, while they were asked to pay particular attention to the vocal hygiene rules presented at the beginning of the study as part of the research process. 
EGG measurement was performed with Kay-PENTAX Electroglottograph model 6103 (Lincoln Park, NJ, USA), and a pair of electrodes with EGG velcro belts were placed by palpating the thyroid notch in the neck areas of the participants. The system is set to 44.100 sampling rate. In this context, the (17) $/ \Lambda /, / \varepsilon /, / i /$ and $/ \mathrm{u} /$ vowels in the phonetic inventory of Turkish were recorded consecutively, each with a minimum of five seconds. For the correct placement of EGG electrodes and adaptation of the person to the process, the person was first asked for sustained phonation of $/ \Lambda /$ to last a minimum of five seconds. In this way, the clinician confirmed both the accuracy of the electrode placement with the morphology $(1,2)$ of the Lx wave appearing on the screen and allowed the person to adapt to the recording procedures. The recording order of the vowels was randomly changed for each participant and each registration session. Two minutes of absolute voice rest and hydration intervals were given between recordings. Recordings were taken once for each vowel, recorded in ".nsp" format, and then the three-second segment in the middle of each recorded vowel phonation was analyzed.

A specific calendar was determined for the measurements in the study: 1. When the measurement was taken between 10:00 and 11:00 in the morning $(1 \mathrm{M})$, 2. the measurement was taken between 16:00 and 17:00 (1E) in the evening, and sessions 1M and $1 \mathrm{E}$ were performed on the same day. The third and fourth measurement sessions were held 1 week after the day of $1 \mathrm{M}$ and $1 \mathrm{E}$ measurements. The third measurement was taken again between 10:00 and 11:00 in the morning (2M), and the fourth measurement was taken again between 16:00 and 17:00 in the evening (2E), and the $2 \mathrm{M}$ and $2 \mathrm{E}$ sessions were also performed on the same day. In this context, measurements were completed in a total of 4 different sessions, provided that they were taken at different times for each participant.

During the recording, the person was asked to sit in an upright position and to perform the vowel phonation requested from him in the same tone and volume used in daily life, without interruption. The parameters to be evaluated in EGG-frequency measurement are mean F0, minimum F0, maximum F0, FO standard deviation, mean jitter and frequency periodicity (periodicity) measurement parameters. The mean, minimum and maximum parameter values of the glottal closure phase (closed phase-CP) and the mean, minimum and maximum parameter values of the glottal opening phase (open phase-OP) were examined. All recording and analysis processes were carried out in Üsküdar University Phonetics Laboratory.

\section{Statistical Analysis}

The SPSS 22.0 package program was used to evaluate the data. While using the intraclass correlation coefficient (ICC), the twoway mixed model was preferred because the participants were randomly selected and the person taking the measurement was fixed. This method is calculated with the formula ICC $(3,1)(18)$. For the normality assumption, the skewness-kurtosis coefficients and Shapiro-Wilks test results were evaluated together. In order to determine whether the measurement parameters differ by gender, independent samples t-test were used because the data showed a normal distribution. In both measurements, the significance level was considered $p<0.05$. According to ICC classification criteria, the reliability of ICC values less than 0.5 is low, values between 0.5 and 0.75 are moderately reliable, values between 0.75 and 0.9 are well reliable, and values greater than 0.9 are perfectly reliable (19). In this context, the current ranges are referenced in the ICC classification to be used during the reporting.

\section{RESULTS}

In order to calculate the test-retest results of parameters $1 \mathrm{E}, 1 \mathrm{M}$, $2 \mathrm{M}$ and $2 \mathrm{E}$ of the $/ \mathrm{\Lambda} /$ vowel, the correlation coefficient in the class was calculated. Results for women are presented in Table 1.

For women, all ICCs calculated except for the frequency periodicity parameter obtained from the $/ \Lambda /$ vowel in accordance with morning $(1 \mathrm{M})$ and evening $(1 \mathrm{E})$ records on the same day are statistically significant $(p<0.05)$. By examining the ICC values obtained for all other parameters, repeated measurements were found to be reliable at moderate and good levels.

One week after the first measurement, all intraclass correlation coefficients were found to be statistically significant except for minimum- $\mathrm{CP}$, maximum-OP and maximum F0 measurements obtained from the $/ \mathrm{N} /$ vowel, based on the recordings taken in the morning $(2 \mathrm{M})$ and evening (2E) on the same day for women. $(p<0.05)$. When the ICC values obtained for all other parameters were examined, repeated measurements were obtained with moderate, good and excellent levels of reliability. All ICCs calculated except the frequency periodicity obtained from the $/ \Lambda /$ vowel in accordance with the records received in the morning $(1 \mathrm{M})$ on the first day and in the morning (2M) a week later are statistically significant $(p<0.05)$. When the ICC values obtained for all other parameters were examined, repeated measurements were obtained reliably at moderate, good and excellent levels. All ICCs calculated except the maximum F0 and frequency periodicity obtained from the $/ \mathrm{N}$ / vowel were statistically significant according to the records obtained in the evening (1E) on the first day and in the evening (2E) a week later $(p<0.05)$. When examining the ICC values obtained for all other parameters, repeated measurements were obtained reliably at moderate, good and excellent levels (Table 1).

In order to calculate the test-retest results of parameters $1 \mathrm{E}, 1 \mathrm{E}$, $2 \mathrm{M}$ and $2 \mathrm{E}$ of the $/ \mathrm{A} /$ vowel, the correlation coefficient in the class was calculated. Results for men are presented in Table 2.

For males, all ICCs were found to be statistically significant except mean-OP, minimum-OP and maximum-OP obtained from the $/ \mathrm{N} /$ vowel based on the morning $(1 \mathrm{M})$ and evening $(1 \mathrm{E})$ recordings on the same day $(p<0.05)$. When the ICC values obtained for all other parameters are examined, it can be said that repeated measurements are reliable at moderate, good and excellent levels. 
One week after the first measurement, all ICCs were statistically significant $(p<0.05)$, except for the average jitter and frequency periodicity obtained in the $/ \Lambda /$ vowel, according to the recordings taken in the morning (2M) and evening (2E) on the same day for men.

When the ICC values obtained for all other parameters were examined, repeated measurements were reliable at low, moderate and good levels. Based on the recordings taken in the morning $(1 \mathrm{M})$ on the first day and in the morning $(2 \mathrm{M})$ a week later, the whole class calculated except the minimum- $\mathrm{CP}$, maximum$\mathrm{CP}$, average- $\mathrm{OP}$, minimum- $\mathrm{OP}$, maximum- $\mathrm{OP}$, Average jitter obtained from the $/ \mathrm{N} /$ intra-correlation coefficients were found to be statistically significant $(p<0.05)$. By examining the ICC values obtained for all other parameters, repeated measurements were obtained reliably at moderate, good and excellent levels. All ICCs obtained from the $/ \mathrm{A} /$ vowel by making evening (1E) on the first day and evening (2E) a week later are statistically significant $(p<0.05)$.
Repeated measurements were reliably obtained at low, moderate and good levels when examining the ICC values obtained for all other parameters (Table 2).

In order to calculate the test-retest results of $1 \mathrm{M}, 1 \mathrm{E}, 2 \mathrm{M}$ and $2 \mathrm{E}$ parameters of the / $/ \varepsilon /$ vowel, the ICC was calculated. Results for women are presented in Table 3.

In addition to the morning $(1 \mathrm{M})$ and evening (1E) recordings on the same day for women, and the morning (2M) and evening (2E) measurements for women one week after the first measurement, on the same day, morning $(1 \mathrm{M})$ and one-week measurements were made. According to the repeated test results of all parameters obtained from the $/ \varepsilon /$ vowel, the intraclass correlation coefficients were found to be statistically significant $(p<0.05)$. In this context, when examining the ICC values obtained for all parameters, repeated measurements were obtained reliably at moderate, good and excellent levels (Table 3).

\section{Table 1. Test-retest results of measurements of the $/ \mathbb{A} /$ vowel for women}

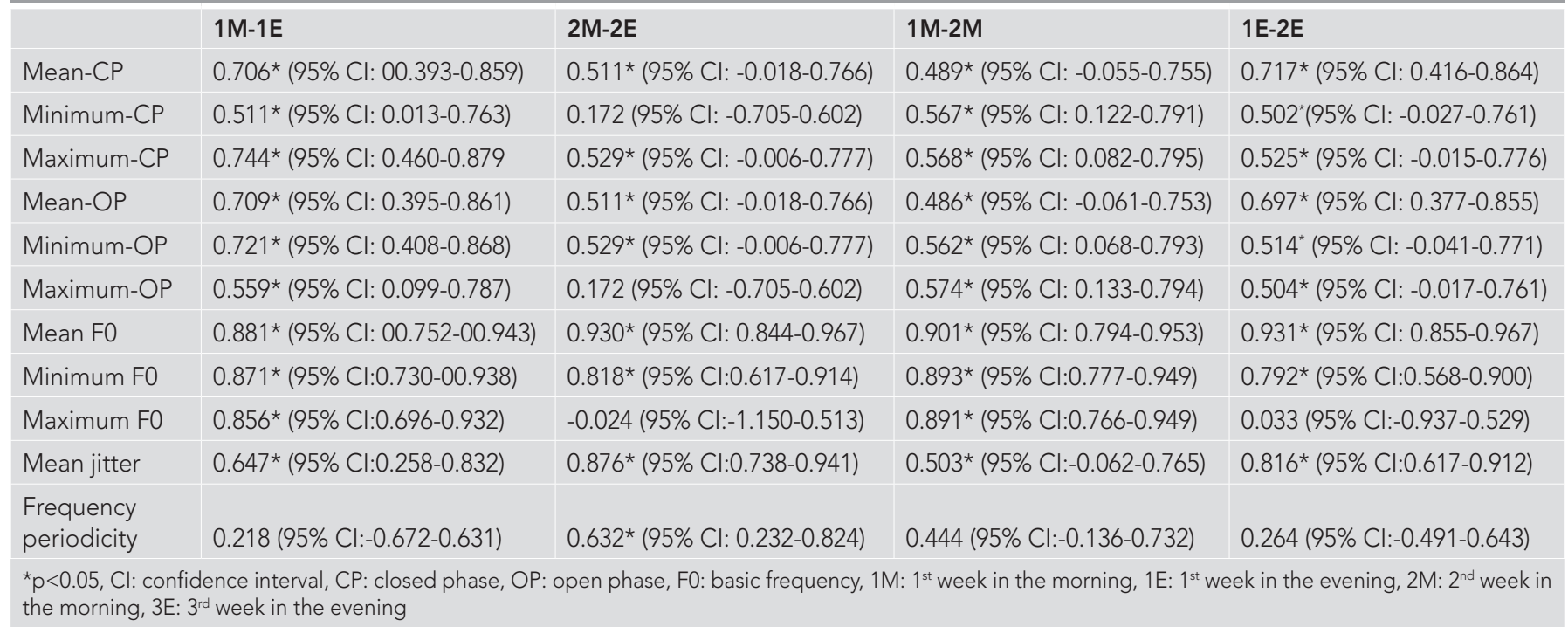

Table 2. Test-retest results of measurements of the $/ \Lambda /$ vowel for men

\begin{tabular}{|c|c|c|c|c|}
\hline & $1 \mathrm{M}-1 \mathrm{E}$ & $2 \mathrm{M}-2 \mathrm{E}$ & $1 \mathrm{M}-2 \mathrm{M}$ & $1 \mathrm{E}-2 \mathrm{E}$ \\
\hline Mean-CP & $0.837 *$ (95\% Cl: 0.656-0.922) & $0.672^{*}(95 \% \mathrm{Cl}: 0.311-0.844)$ & $0.620 *(95 \% \mathrm{Cl}: 0.190-0.820)$ & $0.773^{*}(95 \% \mathrm{Cl}: 0.523-0.892)$ \\
\hline Minimum-CP & $0.545^{\star}(95 \% \mathrm{Cl}: 0.048-0.783)$ & $0.498 *(95 \%$ Cl:-0.068-0.763) & 0.341 (95\% Cl:-0.419-0.690) & 0.706 (95\% Cl: 0.395-0.859) \\
\hline Mean-OP & 0.307 (95\% Cl:-0.469-0.672) & $0.754^{*}(95 \% \mathrm{Cl}: 0.491-0.882)$ & 0.009 (95\% Cl:-1.119-0.532) & $0.768 *$ (95\% Cl: $0.520-0.889)$ \\
\hline Minimum-OP & 0.374 (95\% Cl:-0.282-0.698) & $0.770 *(95 \% \mathrm{Cl}: 0.509-0.891)$ & 0.079 (95\% Cl:-0.900-0.558) & $0.775^{\star}$ (95\% Cl: 0.512-0.894) \\
\hline Mean F0 & $0.932 *$ (95\% Cl: 0.773-0.974) & $0.895^{\star}(95 \% \mathrm{Cl}: 0.779-0.950)$ & $0.907 *$ (95\% Cl:0.807-0.956) & $0.858 *$ (95\% Cl: 0.702-0.932) \\
\hline Minimum F0 & $0.882 *$ (95\% Cl: 0.658-0.951) & $0.878 *(95 \% \mathrm{Cl}: 0.746-0.942)$ & $0.844^{*}(95 \% \mathrm{Cl}: 0.675-0.926)$ & 0.850 * (95\% Cl: 0.684-0.929) \\
\hline Maximum F0 & $0.839 *$ (95\% Cl: 0.663-0.923) & $0.892 *(95 \% \mathrm{Cl}: 0.773-0.949)$ & $0.802 *(95 \% \mathrm{Cl}: 0.580-0.906)$ & $0.843^{*}(95 \%$ Cl: 0.673-0.925) \\
\hline Mean jitter & $0.752^{*}(95 \% \mathrm{Cl}: 0.488-0.881)$ & 0.170 (95\% Cl:-0.722-0.603) & 0.140 (95\% Cl:-0.832-0.593) & $0.595^{\star}(95 \% \mathrm{Cl}: 0.146-0.807)$ \\
\hline $\begin{array}{l}\text { Frequency } \\
\text { periodicity }\end{array}$ & $0.857 *$ (95\% Cl: 0.699-0.932) & 0.448 (95\% Cl:-0.180-0.740) & $0.673^{*}(95 \% \mathrm{Cl}: 0.311-0.845)$ & $0.462 *(95 \%$ Cl:-0.107-0.742) \\
\hline
\end{tabular}


In order to calculate the test-retest results of $1 \mathrm{M}, 1 \mathrm{E}, 2 \mathrm{M}$ and $2 \mathrm{E}$ parameters of the / $\varepsilon /$ vowel, the ICC was calculated. Results for men are presented in Table 4.

In addition to the morning $(1 \mathrm{M})$ and evening $(1 \mathrm{E})$ recordings on the same day for men, and the morning (2M) and evening (2E) recordings one week after the first measurement for women, on the same day for women, the first day morning $(1 \mathrm{M})$ and ICCs were statistically significant $(p<0.05)$, according to the repeated test results of all parameters obtained from the $/ \varepsilon /$ vowel, according to the recordings taken in the morning (2M) after a week, in the evening (1E) on the first day, and in the evening (2E) one week later. In this context, when examining the ICC values obtained for all parameters, repeated measurements were obtained reliably at moderate, good and excellent levels (Table 4).

In order to calculate the test-retest results of $1 \mathrm{M}, 1 \mathrm{E}, 2 \mathrm{M}$ and $2 \mathrm{E}$ parameters of the /i/ vowel, the ICC was calculated. Results for women are presented in Table 5.
For women, all ICCs calculated except maximum-CP and minimum-OP obtained from the /i/ vowel in accordance with morning $(1 \mathrm{M})$ and evening $(2 \mathrm{E})$ records on the same day are statistically significant $(p<0.05)$. By examining the ICC values obtained for all other parameters, repeated measurements were obtained reliably at moderate and good levels. One week after the first measurement, all ICCs, except minimum-CP and maximum-OP obtained in the / $\mathrm{i} /$ vowel, were statistically significant, based on the recordings taken in the morning (2M) and evening (2E) on the same day for women. When the ICC values obtained for all other parameters were examined, repeated measurements were obtained with moderate and excellent levels of reliability. All ICCs obtained from the /i/ vowel are statistically significant according to the records taken in the morning $(1 \mathrm{M})$ on the first day and in the morning (2M) a week later $(p<0.05)$. By examining the ICC values obtained for all parameters, repeated measurements were obtained reliably at moderate and excellent levels. It can be said that the measurements obtained for these parameters are reliable.

\begin{tabular}{|c|c|c|c|c|}
\hline & 1M-1E & $2 \mathrm{M}-2 \mathrm{E}$ & $1 \mathrm{M}-2 \mathrm{M}$ & $1 \mathrm{E}-2 \mathrm{E}$ \\
\hline Mean-CP & $0.735^{\star}$ (95\% Cl:0.449-0.873) & $0.776^{*}(95 \%$ Cl:0.533-0.893) & $0.740 *$ (95\% Cl:0.455-0.876) & $0.676^{\star}(95 \% \mathrm{Cl}: 0.318-0.846)$ \\
\hline Maximum-CP & $0.641 *$ (95\% Cl:0.240-0.830) & $0.724 *$ (95\% Cl:0.429-0.868) & $0.736 *$ (95\% Cl:0.443-0.874) & $0.707 *$ (95\% Cl:0.395-0.859) \\
\hline Mean-OP & $0.747 *(95 \%$ Cl:0.466-0.880) & $0.813^{*}(95 \% \mathrm{Cl}: 0.607-0.911)$ & $0.772 *$ (95\% Cl:0.528-0.891) & $0.633^{*}(95 \% \mathrm{Cl}: 0.239-0.824)$ \\
\hline Maximum-OP & $0.788 *$ (95\% Cl:0.559-0.898) & $0.647 *$ (95\% Cl:0.249-0.833) & $0.749 *$ (95\% Cl:0.475-0.880) & $0.538 *(95 \% \mathrm{Cl}: 0.038-0.779)$ \\
\hline Mean F0 & $0.881 *$ (95\% Cl:0.751-0.943) & $0.923^{\star}(95 \% \mathrm{Cl}: 0.839-0.963)$ & $0.868^{\star}(95 \% \mathrm{Cl}: 0.726-0.937)$ & $0.915^{\star}(95 \% \mathrm{Cl}: 0.824-0.960)$ \\
\hline Minimum F0 & $0.723^{*}(95 \% \mathrm{Cl}: 0.427-0.867)$ & $0.918^{*}(95 \% \mathrm{Cl}: 0.829-0.961)$ & $0.862^{*}(95 \% \mathrm{Cl}: 0.713-0.934)$ & $0.688^{*}(95 \% \mathrm{Cl}: 0.359-0.850)$ \\
\hline Maximum F0 & $0.869 *$ (95\% Cl:0.727-0.937) & $0.909 *$ (95\% Cl:0.811-0.957) & $0.856^{*}(95 \% \mathrm{Cl}: 0.701-0.931)$ & $0.908^{*}(95 \% \mathrm{Cl}: 0.809-0.956)$ \\
\hline Mean jitter & $0.924 *$ (95\% Cl:0.842-0.964) & $0.868^{*}(95 \%$ Cl:0.723-0.937) & $0.717 *(95 \%$ Cl:0.398-0.866) & $0.788^{*}(95 \% \mathrm{Cl}: 0.551-0.899)$ \\
\hline
\end{tabular}

\section{Table 4. Test-retest results of measurements of the $/ \varepsilon /$ vowel for men}

\begin{tabular}{|c|c|c|c|c|}
\hline & $1 \mathrm{M}-1 \mathrm{E}$ & $2 \mathrm{M}-2 \mathrm{E}$ & $1 \mathrm{M}-2 \mathrm{M}$ & $1 \mathrm{E}-2 \mathrm{E}$ \\
\hline Mean-CP & $0.812 *(95 \% \mathrm{Cl}: 0.607-0.911)$ & $0.754^{*}(95 \% \mathrm{Cl}: 0.485-0.883)$ & $0.728 *(95 \% \mathrm{Cl}: 0.430-0.870)$ & $0.511^{*}(95 \% \mathrm{Cl}:-0.039-0.769)$ \\
\hline Minimum-CP & $0.743^{*}(95 \% \mathrm{Cl}: 0.458-0.878)$ & $0.665^{\star}(95 \% \mathrm{Cl}: 0.288-0.842)$ & $0.525 *$ (95\% Cl:0.018-0.772) & $0.474^{*}(95 \%$ Cl:-0.115-0.750) \\
\hline Maximum-CP & 0.855* (95\% Cl:0.696-0.931) & $0.701 *(95 \% \mathrm{Cl}: 0.382-0.857)$ & $0.742 *$ (95\% Cl:0.459-0.877) & $0.549 *$ (95\% Cl:0.051-0.785) \\
\hline Mean-OP & 0.689* (95\% Cl:0.339-0.853) & $0.838 *$ (95\% Cl:0.657-0.923) & $0.728 *(95 \% \mathrm{Cl}: 0.431-0.870)$ & $0.645^{\star}(95 \% \mathrm{Cl}: 0.255-0.831)$ \\
\hline Minimum-OP & $0.723 *$ (95\% Cl:0.414-0.869) & $0.782 *$ (95\% Cl:0.544-0.896) & $0.742 *(95 \% \mathrm{Cl}: 0.459-0.877)$ & $0.667 *$ (95\% Cl:0.294-0.842) \\
\hline Maximum-OP & $0.617 *(95 \% \mathrm{Cl}: 0.185-0.819)$ & $0.745^{\star}(95 \% \mathrm{Cl}: 0.469-0.878)$ & $0.527 *(95 \% \mathrm{Cl}: 0.023-0.773)$ & $0.628^{\star}(95 \% \mathrm{Cl}: 0.237-0.821)$ \\
\hline Mean FO & $0.902 *(95 \% \mathrm{Cl}: 0.796-0.953)$ & $0.909 *$ (95\% Cl: 0.808-0.957) & $0.865^{\star}(95 \% \mathrm{Cl}: 0.716-0.936)$ & $0.869 *$ (95\% Cl:0.727-0.937) \\
\hline Minimum F0 & $0.893^{*}(95 \% \mathrm{Cl}: 0.777-0.949)$ & $0.899 *$ (95\% Cl: $0.786-0.952)$ & $0.860 *$ (95\% Cl:0.704-0.933) & 0.856* (95\% Cl:0.699-0.931) \\
\hline Maximum F0 & $0.908 *(95 \% \mathrm{Cl}: 0.807-0.956)$ & $0.909 *$ (95\% Cl: $0.808-0.957)$ & $0.870 *(95 \% \mathrm{Cl}: 0.726-0.938)$ & $0.875^{\star}$ (95\% Cl:0.740-0.940) \\
\hline Mean jitter & $0.864^{*}(95 \% \mathrm{Cl}: 0.715-0.935)$ & $0.892^{\star}(95 \% \mathrm{Cl}: 0.720-0.918)$ & $0.734^{*}(95 \%$ Cl: 0.691-0.882) & $0.714^{*}$ (95\% Cl:0.410-0.863) \\
\hline Frequency periodicity & 0.585* (95\% Cl:0.117-0.803) & $0.616^{*}(95 \% \mathrm{Cl}: 0.187-0.818)$ & $0.678 *(95 \% \mathrm{Cl}: 0.331-0.846)$ & $0.715^{\star}(95 \%$ Cl:0.412-0.863) \\
\hline
\end{tabular}


All ICCs calculated except minimum-CP and maximum-OP obtained from the /i/ vowel in accordance with the records obtained in the evening (1E) on the first day and evening (2E) a week later are statistically significant $(p<0.05)$. When examining the ICC values obtained for all other parameters, repeated measurements were obtained reliably at moderate and good levels (Table 5).

In order to calculate the test-retest results of $1 \mathrm{M}, 1 \mathrm{E}, 2 \mathrm{M}$ and $2 \mathrm{E}$ parameters of the /i/ vowel, the ICC was calculated. Results for men are presented in Table 6 .

In addition to the morning (1M) and evening (1E) recordings on the same day for men, and the morning (2M) and evening (2E) recordings for women one week after the first measurement, on the same day, in the morning $(1 \mathrm{M})$ and one week ICCs were statistically significant $(p<0.05)$, according to the repeated test results of all parameters obtained from the $/ \varepsilon /$ vowel, according to the recordings taken in the morning (2M) after the first day and in the evening (1E) on the first day and in the evening (2E) one week later. In this context, when examining the ICC values obtained for all parameters, repeated measurements were obtained reliably at moderate, good and excellent levels (Table 6).

In order to calculate the test-retest results of $1 \mathrm{M}, 1 \mathrm{E}, 2 \mathrm{M}$ and $2 \mathrm{E}$ parameters of the /u/ vowel, the ICC was calculated. Results for women are presented in Table 7.

All ICCs calculated for women, except frequency periodicity obtained from / $u /$ vowel, were statistically significant $(p<0.05)$, based on the recordings taken in the morning $(1 \mathrm{M})$ and evening (1E) on the same day. When the ICC values obtained for all other parameters were examined, repeated measurements were obtained with a good level of reliability. All ICCs calculated for women one week after the first measurement, except for the average jitter obtained from the / $\mathrm{u} /$ vowel in accordance with morning (2M) and evening (2E) records on the same day, are statistically significant $(p<0.05)$. By examining the ICC values

\section{Table 5. Test-retest results of measurements of the /i/ vowel for women}

\begin{tabular}{|c|c|c|c|c|}
\hline & $1 \mathrm{M}-1 \mathrm{E}$ & $2 \mathrm{M}-2 \mathrm{E}$ & $1 \mathrm{M}-2 \mathrm{M}$ & $1 \mathrm{E}-2 \mathrm{E}$ \\
\hline Mean-CP & $0.754^{*}(95 \% \mathrm{Cl}: 0.479-0.883)$ & $0.683^{*}(95 \% \mathrm{Cl}: 0.325-0.850)$ & $0.774 *$ (95\% Cl:0.521-0.893) & 0.641 * (95\% Cl:0.239-0.830) \\
\hline Minimum-CP & $0.652 *(95 \% \mathrm{Cl}: 0.260-0.835)$ & 0.441 (95\% Cl:-0.180-0.734) & $0.639 *(95 \% \mathrm{Cl}: 0.250-0.827)$ & 0.418 (95\% Cl:-0.250-0.726) \\
\hline Mean-OP & $0.754^{*}(95 \% \mathrm{Cl}: 0.478-0.883)$ & $0.690 *(95 \% \mathrm{Cl}: 0.340-0.853)$ & $0.774^{*}(95 \% \mathrm{Cl}: 0.522-0.893)$ & $0.636 *(95 \% \mathrm{Cl}: 0.224-0.828)$ \\
\hline Minimum-OP & 0.444 (95\% Cl:-0.168-0.736) & $0.743 *(95 \% \mathrm{Cl}: 0.457-0.878)$ & $0.874^{*}(95 \% \mathrm{Cl}: 0.736-0.940)$ & $0.497 *(95 \% \mathrm{Cl}:-0.060-0.761)$ \\
\hline Mean F0 & $0.810 *$ (95\% Cl:0.597-0.910) & $0.951 *(95 \%$ Cl:0.897-0.977) & $0.842^{*}(95 \% \mathrm{Cl}: 0.666-0.925)$ & $0.874^{*}(95 \% \mathrm{Cl}: 0.734-0.940)$ \\
\hline Minimum F0 & $0.662 *(95 \%$ Cl:0.290-0.839) & $0.944 *$ (95\% Cl:0.881-0.973) & $0.856 *(95 \% \mathrm{Cl}: 0.697-0.932)$ & $0.653^{*}(95 \% \mathrm{Cl}: 0.270-0.835)$ \\
\hline Maximum F0 & $0.790 *$ (95\% Cl:0.556-0.900) & $0.944^{*}(95 \%$ Cl:0.884-0.973) & $0.820 *$ (95\% Cl:0.619-0.914) & $0.854^{*}(95 \% \mathrm{Cl}: 0.694-0.930)$ \\
\hline Mean jitter & $0.656 *(95 \% \mathrm{Cl}: 0.294-0.834)$ & $0.615^{\star}(95 \% \mathrm{Cl}: 0.211-0.814)$ & $0.745^{\star}(95 \% \mathrm{Cl}: 0.468-0.878)$ & $0.824^{*}(95 \% \mathrm{Cl}: 0.631-0.916)$ \\
\hline $\begin{array}{l}\text { Frequency } \\
\text { periodicity }\end{array}$ & $0.787 *$ (95\% Cl:0.558-0.898) & $0.711 *(95 \%$ Cl:0.391-0.862) & $0.560 *(95 \% \mathrm{Cl}:-0.063-0.734)$ & $0.583^{*}(95 \% \mathrm{Cl}:-0.029-0.747)$ \\
\hline
\end{tabular}

\section{Table 6. Test-retest results of measurements of the /i/ vowel for men}

\begin{tabular}{|c|c|c|c|c|}
\hline & $1 \mathrm{M}-1 \mathrm{E}$ & $2 \mathrm{M}-2 \mathrm{E}$ & $1 \mathrm{M}-2 \mathrm{M}$ & $1 \mathrm{E}-2 \mathrm{E}$ \\
\hline Mean-CP & $0.876 *(95 \% \mathrm{Cl}: 0.741-0.941)$ & $0.827^{\star}(95 \% \mathrm{Cl}: 0.635-0.918)$ & $0.675^{\star}(95 \% \mathrm{Cl}: 0.327-0.844)$ & 0.751 * (95\% Cl:0.474-0.882) \\
\hline Minimum-CP & $0.836 *(95 \% \mathrm{Cl}: 0.653-0.922)$ & $0.823^{*}(95 \% \mathrm{Cl}: 0.627-0.916)$ & $0.568^{*}(95 \% \mathrm{Cl}: 0.125-0.790)$ & $0.758 *(95 \% \mathrm{Cl}: 0.477-0.886)$ \\
\hline Mean-OP & $0.838 *$ (95\% Cl:0.661-0.923) & $0.828^{*}(95 \% \mathrm{Cl}: 0.635-0.918)$ & $0.627 *$ (95\% Cl:0.219-0.822) & $0.752 *(95 \% \mathrm{Cl}: 0.475-0.882)$ \\
\hline Minimum-OP & $0.827^{*}(95 \% \mathrm{Cl}: 0.636-0.918)$ & $0.828^{*}(95 \% \mathrm{Cl}: 0.637-0.918)$ & $0.706^{*}(95 \% \mathrm{Cl}: 0.380-0.860)$ & $0.770 *$ (95\% Cl:0.512-0.891) \\
\hline Mean F0 & $0.920 *(95 \% \mathrm{Cl}: 0.832-0.962)$ & $0.905^{\star}(95 \% \mathrm{Cl}: 0.801-0.955)$ & $0.893^{\star}(95 \% \mathrm{Cl}: 0.775-0.949)$ & $0.863^{*}(95 \% \mathrm{Cl}: 0.712-0.935)$ \\
\hline Minimum F0 & $0.923^{*}(95 \% \mathrm{Cl}: 0.838-0.963)$ & $0.902^{\star}(95 \% \mathrm{Cl}: 0.794-0.953)$ & $0.891 *$ (95\% Cl:0.771-0.948) & $0.855^{\star}(95 \% \mathrm{Cl}: 0.697-0.931)$ \\
\hline Maximum F0 & $0.920 *(95 \% \mathrm{Cl}: 0.834-0.962)$ & $0.911^{\star}(95 \% \mathrm{Cl}: 0.814-0.958)$ & $0.900 *(95 \% \mathrm{Cl}: 0.790-0.953)$ & $0.870 *(95 \% \mathrm{Cl}: 0.728-0.938)$ \\
\hline Mean jitter & $0.901 *$ (95\% Cl:0.792-0.953) & $0.825^{\star}(95 \% \mathrm{Cl}: 0.630-0.917)$ & $0.866 *$ (95\% Cl:0.721-0.936) & $0.802 *(95 \%$ Cl:0.588-0.905) \\
\hline Frequency periodicity & $0.687 *$ (95\% Cl:0.335-0.852) & $0.651^{*}(95 \% \mathrm{Cl}: 0.266-0.834)$ & 0.650 (95\% Cl:0.263-0.833) & $0.526 *(95 \% \mathrm{Cl}: 0.036-0.771)$ \\
\hline
\end{tabular}


obtained for all other parameters, repeated measurements were obtained with low, moderate, good and excellent reliability. All ICCs calculated except mean-OP, minimum-OP and frequency periodicity obtained from /u/ vowel in accordance with the records taken in the morning $(1 \mathrm{M})$ on the first day and in the morning $(2 \mathrm{M})$ a week later are statistically significant $(p<0.05)$. By examining the ICC values obtained for all other parameters, repeated measurements were obtained with low, moderate and good reliability. All ICCs calculated except the average jitter obtained from the $/ \mathrm{u} / \mathrm{vowel}$ in accordance with the records taken in the evening (1E) on the first day and in the evening (2E) a week later are statistically significant $(p<0.05)$. When examining the ICC values obtained for all other parameters, repeated measurements were obtained as moderate and good reliable (Table 7).

To calculate the test-retest results of $1 \mathrm{M}, 1 \mathrm{E}, 2 \mathrm{M}$ and $2 \mathrm{E}$ parameters of the / $\mathrm{u} /$ vowel, the ICC was calculated. Results for men are presented in Table 8.
For men, all ICCs calculated except minimum-CP, maximum-OP and average Jitter obtained in / $\mathrm{u} /$ vowel according to morning $(1 \mathrm{M})$ and evening $(1 \mathrm{E})$ records on the same day are statistically significant $(p<0.05)$. By examining the ICC values obtained for all other parameters, repeated measurements were obtained with moderate and good reliability. All ICCs obtained from the /u/ vowel are statistically significant according to the records taken in the morning $(2 \mathrm{M})$ and evening (2E) on the same day for men one week after the first measurement $(p<0.05)$. By examining the ICC values obtained for all parameters, it can be said that repeated measurements are moderately and well reliable. All ICCs calculated except the average jitter obtained from the / $\mathrm{u} / \mathrm{vowel}$ in accordance with the records taken in the morning $(1 \mathrm{M})$ on the first day and in the morning $(2 \mathrm{M})$ a week later are statistically significant $(p<0.05)$. When the ICC values obtained for all other parameters were examined, repeated measurements were obtained with moderate and good reliability. All ICCs, except maximum FO

\section{Table 7. Test-retest results of measurements of the /u/ vowel for women}

\begin{tabular}{|c|c|c|c|c|}
\hline & $1 \mathrm{M}-1 \mathrm{E}$ & $2 M-2 E$ & $1 \mathrm{M}-2 \mathrm{M}$ & $1 \mathrm{E}-2 \mathrm{E}$ \\
\hline Mean-CP & $0.857^{*}(95 \% \mathrm{Cl}: 0.701-0.932)$ & $0.841 *(95 \% \mathrm{Cl}: 0.661-0.925)$ & $0.827 *$ (95\% Cl:0.640-0.917) & $0.889 *(95 \% \mathrm{Cl}: 0.770-0.947)$ \\
\hline Minimum-CP & $0.798 *(95 \% \mathrm{Cl}: 0.573-0.904)$ & $0.767 *$ (95\% Cl:0.516-0.889) & $0.780 *$ (95\% Cl:0.535-0.896) & $0.842 *$ (95\% Cl:0.671-0.924) \\
\hline Maximum-CP & $0.734^{*}(95 \% \mathrm{Cl}: 0.441-0.873)$ & $0.761 *(95 \% \mathrm{Cl}: 0.506-0.885)$ & $0.723^{*}(95 \% \mathrm{Cl}: 0.428-0.867)$ & $0.807 *$ (95\% Cl:0.596-0.908) \\
\hline Mean-OP & $0.843^{*}(95 \% \mathrm{Cl}: 0.670-0.925)$ & $0.492 *$ (95\% Cl:-0.019-0.753) & 0.300 (95\% Cl:-0.418-0.661) & 0.884 (95\% Cl:0.758-0.944) \\
\hline Minimum-OP & $0.741^{*}(95 \% \mathrm{Cl}: 0.456-0.877)$ & $0.459 *(95 \%$ Cl:-0.093-0.737) & 0.243 (95\% Cl:-0.529-0.633) & $0.786 *(95 \% \mathrm{Cl}: 0.551-0.898)$ \\
\hline Maximum-OP & $0.759 *$ (95\% Cl:0.492-0.886) & $0.473^{*}(95 \%$ Cl:-0.085-0.747) & $0.468 *(95 \%$ Cl:-0.111-0.746) & $0.849 *(95 \% \mathrm{Cl}: 0.686-0.928)$ \\
\hline Mean F0 & $0.888 *$ (95\% Cl:0.763-0.947) & $0.938 *$ (95\% Cl:0.870-0.971) & $0.880 *(95 \% \mathrm{Cl}: 0.746-0.943)$ & $0.857 *$ (95\% Cl:0.698-0.932) \\
\hline Minimum F0 & $0.885^{\star}(95 \% \mathrm{Cl}: 0.758-0.946)$ & $0.941 *$ (95\% Cl:0.876-0.972) & $0.880 *(95 \% \mathrm{Cl}: 0.747-0.943)$ & $0.861 *(95 \% \mathrm{Cl}: 0.706-0.934)$ \\
\hline Maximum F0 & $0.885^{\star}(95 \% \mathrm{Cl}: 0.756-0.945)$ & 0.937* (95\% Cl:0.866-0.970) & $0.889 *$ (95\% Cl:0.765-0.947) & $0.857 *$ (95\% Cl:0.697-0.932) \\
\hline Mean jitter & $0.722^{\star}(95 \% \mathrm{Cl}: 0.422-0.867)$ & 0.415 (95\% Cl:-0.229-0.722) & 0.859* (95\% Cl:0.703-0.933) & 0.232 (95\% Cl:-0.497-0.621) \\
\hline $\begin{array}{l}\text { Frequency } \\
\text { periodicity }\end{array}$ & 0.437 (95\% Cl:-0.133-0.726) & 0.576 (95\% Cl:0.094-0.800) & 0.325 (95\% Cl:-0.338-0.669) & $0.507 *(95 \% \mathrm{Cl}:-0.053-0.767)$ \\
\hline
\end{tabular}

Table 8. Test retest results of measurements of the /u/ vowel for men

\begin{tabular}{|c|c|c|c|c|}
\hline & $1 \mathrm{M}-1 \mathrm{E}$ & $2 \mathrm{M}-2 \mathrm{E}$ & $1 \mathrm{M}-2 \mathrm{M}$ & $1 \mathrm{E}-2 \mathrm{E}$ \\
\hline Mean-CP & $0.857 *$ (95\% Cl:0.701-0.932) & $0.841 *$ (95\% Cl:0.661-0.925) & $0.827 *$ (95\% Cl:0.640-0.917) & $0.889 *$ (95\% Cl:0.770-0.947) \\
\hline Minimum-CP & $0.798 *(95 \% \mathrm{Cl}: 0.573-0.904)$ & $0.767^{*}(95 \% \mathrm{Cl}: 0.516-0.889)$ & 0.780 * (95\% Cl:0.535-0.896) & $0.842^{*}(95 \% \mathrm{Cl}: 0.671-0.924)$ \\
\hline Mean-OP & $0.843^{*}(95 \% \mathrm{Cl}: 0.670-0.925)$ & $0.492^{*}(95 \% \mathrm{Cl}:-0.019-0.753)$ & 0.300 (95\% Cl:-0.418-0.661) & $0.884^{*}(95 \% \mathrm{Cl}: 0.758-0.944)$ \\
\hline Minimum-OP & 0.741 * (95\% Cl:0.456-0.877) & $0.459 *(95 \%$ Cl:-0.093-0.737) & 0.243 (95\% Cl:-0.529-0.633) & $0.786 *$ (95\% Cl:0.551-0.898) \\
\hline Mean FO & $0.888 *(95 \% \mathrm{Cl}: 0.763-0.947)$ & 0.938* (95\% Cl:0.870-0.971) & $0.880 *$ (95\% Cl:0.746-0.943) & $0.857^{\star}$ (95\% Cl:0.698-0.932) \\
\hline Minimum F0 & $0.885^{\star}(95 \% \mathrm{Cl}: 0.758-0.946)$ & $0.941^{*}(95 \% \mathrm{Cl}: 0.876-0.972)$ & $0.880 *$ (95\% Cl:0.747-0.943) & 0.861 * (95\% Cl:0.706-0.934) \\
\hline Maximum F0 & $0.885^{\star}(95 \% \mathrm{Cl}: 0.756-0.945)$ & 0.937 * $(95 \% \mathrm{Cl}: 0.866-0.970)$ & $0.889 *(95 \% \mathrm{Cl}: 0.765-0.947)$ & $0.857 *$ (95\% Cl:0.697-0.932) \\
\hline Mean jitter & $0.722 *(95 \% \mathrm{Cl}: 0.422-0.867)$ & 0.415 (95\% Cl:-0.229-0.722) & 0.859* (95\% Cl:0.703-0.933) & 0.232 (95\% Cl:-0.497-0.621) \\
\hline $\begin{array}{l}\text { Frequency } \\
\text { periodicity }\end{array}$ & 0.437 (95\% Cl:-0.133-0.726) & 0.576 (95\% Cl:0.094-0.800) & 0.325 (95\% Cl:-0.338-0.669) & $0.507 *$ (95\% Cl:-0.053-0.767) \\
\hline
\end{tabular}


participants, reported that there was no significant difference in the test-retest results for laryngeal resistance, mean aiflow and subglottal pressure parameters as a result of the measurements they made on two consecutive days. Lee et al. (12), reported testretest data (28 days apart) for various acoustic and aerodynamic measurements such as volume, airflow rate, and maximum phonation time and showed no significant difference between the measurements. Garrison (13) evaluated the test-retest reliability of various aerodynamic measurements as a result of tests performed at intervals of ten minutes and one week and stated that there was no significant test-retest difference between the parameters measured at different times. In another study, 30 female and 30 male participants stated that the aerodynamic parameters obtained with the Kay-PENTAX Phonatory Aerodynamic System device were good and excellent in the reliability of repeated tests measured one week apart (14).

Unlike the studies mentioned above to prove test-retest reliability, Higgins et al. (15) examined aerodynamic and electroglottographic reliability through variation coefficients among 21 participants (11 male and 10 female) recorded over four non-consecutive days. As a result, the authors noted that there may be no respiratory control in individuals whose subglottal pressures vary by more than $15 \%$ between repeated measurements. In addition, 10\% more than the abduction and fundamental frequency that vary with the rate of $25 \%$ (for syllable repetition) showing more variability caused by tissue damage or a possible situations of glottal air flow may reflect a disorder of vocal fold neuropathology stated that. In this context, the researchers stated that the open phase ratio studied as a result of repeated measurements made at different times was one of the parameters that showed the least change, while the average phonatory aifflow was one of the parameters that showed the most change (15). On the other hand, some researchers stated that values related to the contact area of the vocal fold gave more reliable results $(1,16)$.

Frequency perturbation parameters such as percent jitter (Jitt), relative average perturbation, pitch perturbation coefficient (PPQ), amplitude perturbation coefficient (Shim), and amplitude perturbation coefficient (APQ), which are different techniques, are often used for pathological voice identification. The EGG technique used in this context measures the motion phases of the vocal fold based on the principle of electrical conductivity of the tissues. It shows the data in the form of a Lx wave reflected on the screen, while it can also express the percentage of available glottal phases in this wave in numerical numbers. It also offers clinicians basic frequency and frequency-dependent perturbation values, as it electrically measures the movement of the vocal fold. In contrast, an acoustic measurement is performed only through a microphone and software that will analyze the voice. But in this case, the information about the movement and/or movement regularity of the vocal fold is measured in-directly, as in the EGG measurement. Because the voice recorded through the microphone for analysis is affected by the different resonance properties of the vocal tract (20-23). In the light of this information, 
some researchers have suggested that EGG measurements may be more efficient in detecting voice disorders and monitoring the therapy/treatment process (23-25). As the reason for this, the researchers stated that the information on vocal fold contact rates to be obtained at the end of EGG measurements could be an effective method in the classification of voice disorders, and they also showed that perturbation parameters related to vocal stability can also be obtained using EGG (24).

EGG studies show that young adult males tend to exhibit higher rates of vocal contact than young adult females (2628). In addition, in the study conducted by Paul et al. (29), it was reported that a similar situation is in question in Indian young adult men compared to women. This coincides with the notion that a decrease in fundamental frequency may result in an increase in the off-phase ratio. In contrast, Orlikoff et al. (30) reported similar closed-phase values for males and females with healthy voices during prolonged vowel production. Similarly, in a study conducted by Faria et al. (31), it was reported that there was no significant difference between men and women in the Brazilian Portuguese speaking population. In our study, when we compared the vowels $/ \mathrm{i} /, / \mathrm{u} /, / \varepsilon /$ and $/ \mathrm{N} /$ by gender, there was no significant difference between the sexes in any vowel phonation in terms of mean OP and CP values in accordance with the literature. In other words, similar mean $\mathrm{CP}$ and $\mathrm{OP}$ values were obtained for both genders.

The periodicity factor determines the periodicity of the voice, and in general, a value greater than 20 indicates a high periodicity; a value less than 20 indicates a low degree of periodicity and thus a potential problem with the evaluation with continuous vowel phonation (32). In this context, a statistically significant difference between men and women was obtained in all other continuous vowel phonations except/u/ vowel. When the average values of this parameter were examined, women showed a high level of frequency periodicity values compared to men.

In addition, when looking at the mean values of frequency periodicity for women, regardless of statistical significance, there is an order of $/ \varepsilon /, / \mathrm{i} /, / \mathrm{N} / \mathrm{l} / \mathrm{u} /$, respectively, from largest to smallest; For men, again, when the average values of frequency periodicity were examined without making any significant difference, it was seen that the values of all vowels were very close to each other.

When the periodicity parameters of the participants were examined individually within the mean value and standard deviation data, no frequency periodicity value of the participants was found below the limit of 20. This is actually an expected result, given the criteria for participants to have a healthy voice, while it can also be interpreted as a parameter that confirms the voice health of participants.

It is noteworthy that the frequency periodicity value of $/ \varepsilon /, / \Lambda /$ and /i/ phonations in female individuals was significantly higher than in men when the values were examined. In addition, it was observed that the periodicity value of the front vowels in female individuals was obtained as the average value of the back vowels, and the voice with the most periodicity was obtained as the $/ \varepsilon /$ vowel.

By examining the ICC values in the parameters of repeated measurements at different times over four different vowel phonations, there are statistically significant and non-significant parameters. Statistically significant parameters show that EGG measurements that repeat at different times are reliable, not affected by variations of voice that are likely to be observed during the day, but are not pathological, while parameters that are not statistically significant show that EGG measurements that repeat at different times are not reliable. In this context, in our study, all parameters of the / $/$ / vowel obtained by EGG measurement and mapped as $1 \mathrm{M}-1 \mathrm{E}, 2 \mathrm{M}-2 \mathrm{E}, 1 \mathrm{M}-2 \mathrm{M}$ and $1 \mathrm{E}$ $2 E$ in terms of time for men and women, and the /i/ vowel as a situation observed only in males. When the repeated measurement results of all EGG parameters were examined, ICC values were obtained as statistically significant. In summary, when the ICC values obtained for all parameters were examined in this study, it was found that repeated measurements were reliable at moderate, good and excellent levels for $/ \varepsilon /$ vowel in common for both genders.

In order for a measurement to be reliable in the clinical area, the results of the soon-repeated test should not be affected by daily non-pathological variations (14). In this context, vowels that gave statistically significant levels of moderate, good and excellent ICC results in each parameter in all repeated measurements were found to be / $/$ / vowels for women and / $\varepsilon /$ and /i/ vowels for men. In addition, EGG's repeated measurements eventually gave the most frequently non-significant ICC values, while the vowel vowel with the lowest reliability rates was determined as $/ \Lambda /$ vowel in both genders.

The reason for the low level of reliability in the $/ \Lambda$ / vowel may be due to the fact that the tongue was positioned low and backward in the production of this vowel. EGG measurement is performed by fastening a pair of superficial electrodes to both laminae of the thyroid cartilage, which is palpable in the neck region, with a Velcro strap, and according to the physical connection hypothesis, the tongue, hyoid bone and larynx are interconnected by muscle and connective tissue. While the forward movement of the tongue indirectly causes the hyoid bone to move forward, pulling the larynx upward, it also increases in F0 with increasing tension in the vocal folds, and vice versa (7). In this context, while the forward movement of the hyoid bone in the vowels where the tongue is positioned forward may have caused the larynx to be positioned anteriorly and upwards, acting within the framework of the physical connection hypothesis, while the vowel vowels in which the tongue is positioned behind may pull the larynx down and backward, reducing its prominence in the neck region. As a result, it can help us conclude that the test-retest reliability of vowel vowels with the front and/or high position of the tongue is higher than vowel vowels with the back and/or low position of the tongue, as it causes EGG electrodes to better grasp the 


\section{REFERENCES}

surface of the larynx. According to the ROC analysis results of EGG parameters obtained from different vowel phonations, the researchers found that mean jitter and periodicity parameters showed higher differential diagnosis performance in front vowels (/ع/ and /i/) compared to back vowels (/N/ and /u/) (33) and this is a finding that confirms our research. In our study, the periodicity parameter of the $/ \varepsilon /$ vowel resulted in the highest value compared to the other vowels in terms of mean value; at the same time, the vowels obtained by placing the tongue in the anterior position of the periodicity parameter in terms of the mean value resulted in higher values than the vowels produced by the placement of the tongue in the posterior position. As a matter of fact, this is one of the findings that can be another predictor of the reliability of EGG evaluations performed with front vowels. In this context, both our ICC results and the results obtained from the frequency periodicity parameter confirm each other in this direction.

\section{Study Limitations}

Additional predictive statistical measurements such as standard error measurement, minimum error and variation coefficient were not calculated in this study. Perceptual evaluation of healthy voice was carried out only by the researcher conducting the recording process, and in this context, additional statistical analyses such as interpersonal measurement reliability for perceptual voice evaluation parameters were not available. Criterion in the selection of participants; EGG periodicity parameter is less than 20.

\section{CONCLUSION}

As a result, in EGG measurements obtained by continuous phonation of $/ \varepsilon /$ vowel for both genders and /i/ vowel for only males, moderate, good and excellent ICC values were obtained in all measurement parameters examined and between the paired measurement times.

This shows that the use of the / $\varepsilon /$ vowel for both genders, especially in the recordings taken with EGG, can give more consistent results in terms of test-retest, regardless of the recording time, compared to other vowels.

Acknowledgement: We would like to thank for his contributions to the writing process, Prof. Dr. Ahmet Konrot, MD. Ceki Paltura and Assoc. Prof Burak Öztürk; and Büşra Erdoğan, a speech-language therapist for her help and contributions during data collection and analysis.

Ethics Committee Approval: For the study, Ethics Committee approval was obtained from Üsküdar University Non-interventional Research Evaluation Board (decision no: 61351342-/2019-216, date: 25.04.2019).

Informed Consent: A written consent form was obtained from all of the individuals who agreed to participate in the study, and the participants were informed about the content of the study.

Peer-review: Externally peer-reviewed.

Author Contributions: Concept - M.E.C., G.Y.; Design - M.E.C., G.Y.; Data Collection and/or Processing - M.E.C., G.Y.; Analysis and/or Interpretation - M.E.C., G.Y.; Literature Search - M.E.C., G.Y.; Writing - M.E.C., G.Y.

Conflict of Interest: The authors have no conflict of interest to declare.

Financial Disclosure: The authors declared that this study has received no financial support.
1. Baken RJ. Electroglottography. J Voice 1992; 6: 98-110.

2. Herbst CT. Electroglottography - sn Update. J Voice 2020; 34: 503-26.

3. Maccallum JK, Zhang Y, Jiang JJ. Vowel selection and its effects on perturbation and nonlinear dynamic measures. Folia Phoniatr Logop 2011; 63: 88-97.

4. Higgins $M B$, Netsell $R$, Schulte L. Vowel-related differences in laryngeal articulatory and phonatory function. J Speech Lang Hear Res 1998; 41: 712-24.

5. Orlikoff RF. Vocal stability and vocal tract configuration: an acoustic and electroglottographic investigation. J Voice 1995; 9: 173-81.

6. Kent RD. Vocal tract acoustics. Journal of Voice 1993; 7: 97-117.

7. Honda K. Relationship between pitch control and vowel articulation. Haskins Laboratories Status Report on Speech Research 1983; 73: $269-82$.

8. Lin E, Jiang J, Noon SD, Hanson DG. Effects of head extension and tongue protrusion on voice perturbation measures. J Voice 2000; 14: 8-16.

9. Howard DM. The real and the non-real in speech measurements. Med Eng Phys. 2002; 24: 493-500.

10. Leeper HA Jr, Graves DK. Consistency of laryngeal airway resistance in adult women. J Commun Disord 1984; 17: 153-63.

11. Wilson JV, Leeper HA. Changes in laryngeal airway resistance in young adult men and women as a function of vocal sound pressure level and syllable context. J Voice 1992; 6: 23545

12. Lee L, Stemple JC, Kizer M. Consistency of acoustic and aerodynamic measures of voice production over 28 days under various testing conditions. J Voice 1999; 13: 477-8.

13. Garrison CR. Repeatability of aerodynamic measurements of voice (dissertation) Miami: Miami Univ. 2009.

14. Awan SN, Novaleski CK, Yingling JR. Test-retest reliability for aerodynamic measures of voice. J Voice 2013; 27: 674-84.

15. Higgins MB, Netsell R, Schulte L. Aerodynamic and electroglottographic measures of normal voice production: intrasubject variability within and across sessions. J Speech Hear Res 1994; 37: 38-45.

16. Winstanley $\mathrm{S}$, Wright $\mathrm{H}$. Vocal fold contact area patterns in normal speakers: an investigation using the electrolaryngograph interface system. Br J Disord Commun 1991; 26: 25-39.

17. Demirhan E, Unsal EM, Yilmaz C, Ertan E. Acoustic voice analysis of young Turkish speakers. J Voice 2016; 30: 378.e21-5

18. Shrout PE, Fleiss JL. Intraclass correlations: uses in assessing rater reliability. Psychol Bull 1979; 86: 420-8.

19. Koo TK, Li MY. A guideline of selecting and reporting intraclass correlation coefficients for reliability research. J Chiropr Med 2016; 15: 155-63.

20. Avelino H. Acoustic and electroglottographic analyses of nonpathological, nonmodal phonation. J Voice 2010; 24: 270-80.

21. Bier SD, Watson $\mathrm{Cl}, \mathrm{McC}$ ann $\mathrm{CM}$. Using the perturbation of the contact quotient of the EGG waveform to analyze age differences in adult speech. J Voice 2014; 28: 267-73.

22. Konstantopoulos K, Vikelis M, Seikel JA, Mitsikostas DD. The existence of phonatory instability in multiple sclerosis: an acoustic and electroglottographic study. Neurol Sci 2010; 31: 259-68.

23. Yamout B, Al-Zaghal Z, El-Dahouk I, Farhat S, Sibai A, Hamdan AL. Mean contact quotient using electroglottography in patients with multiple sclerosis. J Voice 2013; 27: 506-11.

24. Villafuerte-Gonzalez R, Valadez-Jimenez VM, Sierra-Ramirez JA, Ysunza PA, Chavarria-Villafuerte K, Hernandez-Lopez X. Acoustic analysis and electroglottography in elite vocal performers. J Voice 2017; 31: 391.e1-6.

25. Hosokawa K, Ogawa M, Hashimoto M, Inohara H. Statistical analysis of the reliability of acoustic and electroglottographic perturbation parameters for the detection of vocal roughness. J Voice 2014; 28: 263. e9-263.e16.

26. Higgins MB, Saxman JH. A comparison of selected phonatory behaviors of healthy aged and young adults. J Speech Hear Res 1991; 34: 1000-10.

27. Ma EP, Love AL. Electroglottographic evaluation of age and gender effects during sustained phonation and connected speech. J Voice 2010; 24: $146-52$

28. Awan SN, Awan JA. The effect of gender on measures of electroglottographic contact quotient. J Voice 2013; 27: 433-40.

29. Paul N, Kumar S, Chatterjee I, Mukherjee B. Electroglottographic parameterization of the effects of gender, ævowel and phonatory 
registers on vocal fold vibratory patterns: an Indian perspective. Indian J Otolaryngol Head Neck Surg 2011; 63: 27-31.

30. Orlikoff RF, Baken RJ, Kraus DH. Acoustic and physiologic characteristics of inspiratory phonation. J Acoust Soc Am 1997; 102: 1838-45.

31. Faria BS, Oliveira KV, Silva JP, Reis C, Ghio A, Gama AC. Electroglottography of speakers of Brazilian Portuguese through Objective Multiparameter Vocal Assessment (EVA). Braz J Otorhinolaryngol 2012; 78: 29-34.
32. Pentax K. (2013). Reel-Time EGG Analysis, model 6103. Software instruction Manual, Issue F. Lincoln Park, NJ, USA.

33. Yılmaz G. Farklı ünlü fonasyonlarına ilişkin akustik ve elektroglottografik ölçüm parametrelerinin karşılaştırılması ve bu parametrelere ait özgüllük ve duyarlılık değerlerinin belirlenmesi. Yüksek Lisans Tezi. Üsküdar Üniversitesi, 2020. 